\title{
HOSPITAL ACQUIRED INFECTIONS IN A MEDICAL INTENSIVE CARE UNIT- A RETROSPECTIVE STUDY
}

KEY WORDS:

\section{Dr Anbarasu.D \\ Dr Nirmal kumar N S* \\ Dr kundana}

\section{INTRODUCTION:}

Infections in critical care unit are high, and of serious hospital problems. Infections acquired during the hospital stay are generally called nosocomial infections, initially known as infections arising after $48 \mathrm{~h}$ of hospital admission.[1,2] National Nosocomial Infections Surveillance system defines a nosocomial infection as a localized or systemic condition that results from adverse reaction to the presence of an infectious agent (s) or its toxin (s) that was not present or incubating at the time of admission to the hospital.[1]

In addition, they impose heavy cost on hospitals causing increased hospitalization time, increased morbidity, and mortality.[3] The risk factors for nosocomial infections include: Diabetes mellitus, intubation, persistent sounding, surgical drains, poor health status, lack of using gloves, irregular and inappropriate debridement and wound bandage. Although the Intensive Care Units (ICUs) account for fewer than $10 \%$ of total beds in most hospitals, more than $20 \%$ of all nosocomial infections are acquired in ICUs.[4]. According to published literature the most prevalent nosocomial infections among patients in ICU are urinary tract infection (UTI), pneumonia, bloodstream infections, skin and soft tissue infections, gastroenteritis, hepatitis and central nervous system infections like meningitis. $[5,6,7,8]$

Hospital acquired infections involves yearly about 2 millions in US and accounts approximately for a cost of 4.5 billion dollars. [3] The magnitude of this problems in a developing country like India is even more serious since there is no available established statistics.

\section{AIMS AND OBJECTIVE}

1. To find out the incidence of nosocomial infections in patients admitted to intensive care unit.

\section{Methodology}

The study was a retrospective analytical study. Methodology involved collection of data of nosocomial infections from patient records, analysis of infections, and their causes. A total of 100 records of patients admitted to ICU of a tertiary health center, Meenakshi medical college hospitals and research institute, Kanchipuram, Tamilnadu during October 2019 to March 2020 were considered. Detailed history and physical examination notes were reviewed in all patients' records. A diagnostic criteria for nosocomial infection by Mukherjee et al.[9] [Table 1] was used for categorizing the cases. Descriptive statistics was used for analysis. Prior permission was obtained from district surgeon and ethical clearance was obtained from Ethical Clearance Committee of Meenakshi medical college hospitals and research institute

Table 1 Diagnostic criteria for nosocomial infections. \begin{tabular}{|l|l|l|}
\hline Nosocomial Infections & Clinical Features Labaratory features \\
\hline
\end{tabular} UTI

\begin{tabular}{|c|c|}
\hline $\begin{array}{c}\text { Fever } \\
\text { Lower } \\
\text { abdominal pain, } \\
\text { change in urine } \\
\text { characteristics }\end{array}$ & $\begin{array}{c}\text { Leukocytosis } \\
\text { Positive urine } \\
\text { culture } 5\end{array}$ \\
\hline
\end{tabular}

\begin{tabular}{|c|c|c|}
\hline Blood Infections & $\begin{array}{c}\text { Unexplained } \\
\text { fever with chills } \\
\text { and rigor pain, } \\
\text { tenderness or } \\
\text { purulent } \\
\text { drainage at the } \\
\text { site of insertion } \\
\text { of IV access or } \\
\text { CVP catheter }\end{array}$ & $\begin{array}{c}\text { Leukocytosis } \\
\text { Positive blood } \\
\text { culture } \\
\text { Positive CVP } \\
\text { catheter } \\
\text { culture(after } \\
\text { catheter removal) }\end{array}$ \\
\hline
\end{tabular}

\section{Results}

This study was conducted on 50 patients in hospital Medical Intensive Care Unit (MICU) admitted during the study period of 6 months. All the patients admitted during this period with intravascular access through CVP catheter/dialysis catheter, Foleys catheter were included in the study. Eight out of 50(8/50-16\%) admitted to the MICU suffered from nosocomial infection, there were 3 male and 5 female. The age ranged from 42 to 71 years, mean age being 56 years. The mean duration of stay of the patient in the hospital was 8 days. Table 2 shows the distribution of the nosocomial infections in those patients.

Table 2 Distribution of nosocomial infections among nosocomial positive patients

\begin{tabular}{|c|c|c|}
\hline $\begin{array}{c}\text { Nosocomial } \\
\text { infections }\end{array}$ & Number of patients & Percentage \\
\hline $\begin{array}{c}\text { Urinary tract } \\
\text { infections }\end{array}$ & 3 & 6 \\
\hline $\begin{array}{c}\text { Blood stream } \\
\text { infections }\end{array}$ & 5 & 10 \\
\hline Total & $8 / 50$ & 16 \\
\hline
\end{tabular}

In our study, it was observed that distribution of nosocomial infections in MICU were UTI (6\% - 3/50), blood stream infections $(10 \%-5 / 50)$

\section{Discussion}

The incidence of Nosocomial infections in our study was $17.69 \%$ similar to hospital record statement of NM hospital and heart center and their own study, mentioned in Pratham et al.[5] Vincent et al.,[10] but less compared to $33.5 \%$ by Beaujean et al.[11] This may be due to the relative small sample size of the present study. The general distribution pattern of the nosocomial infections in our study showed bloodstream infections to be the most common, followed by UTI.

Female patients were predominant in the present study with overall mean age being 56 years. The increase incidence in geriatric age group may be due to their defective host defense mechanism. Similarly with respect to the role played by invasive devices in contributing to nosocomial infections, present study showed that $62.5 \%$ of UTI occurred in catheterized patients and $100 \%$ of bloodstream infections with catheters could be attributed to the use of invasive devices. The findings were similar to Richards et al.,[2] Pratham et al.,[5] Suman.[12] 
Intensive care unit acquired infections account for substantial morbidity, mortality, and expensive. Nosocomial infections increase the cost of healthcare in the countries least able to afford them through increased: Length of hospitalization; treatment with expensive medications (e.g. antibiotics); and use of other services (e.g. laboratory tests, X-rays and transfusions).[13]

Major infections found in ICU were due to Acinetobacter baumannii, Escherichia coli, Klebsiella pneumoniae, Pseudomonas aeruginosa, Staphylococcus aureus and Streptococcus pyogenes.[14] The infection rate was maximum in the urinary tract $(44.4 \%)$ followed by wound infections (29.4\%), pneumonia (10.7\%) and bronchitis (7.4\%). A. baumannii was found to be associated with UTIs, respiratory tract infections, septicemia, bacteremia, meningitis and wound infections. A. Baumannii displayed higher resistance to more number of antibiotics than other nosocomial pathogens from ICU. Hence, it is very important to target the nosocomial infections. [14]

Main problems in developing countries are understaffing, poor infrastructure in ICU and poor maintenance of records making situation difficult to get clarity on the incidence of these infections. Although it is difficult to solve some problems associated with financial hardship in developing countries, most solutions are simple and not resource demanding. Infection control strategies such as hand hygiene and wearing gloves; paying attention to well established processes for decontamination and cleaning of soiled instruments and other items, followed by either sterilization or high-level disinfection; and improving safety in operating rooms and other high-risk areas where the most serious and frequent injuries and exposures to infectious agents can resolve the problem to a major extent.

\section{Limitation}

Even though the sample size was very less, unequal distribution of samples according to gender and age due to which exact prevalence of nosocomial infections was not calculated for independent variables, nosocomial infections mere presence among the present study cases cannot be ruled out. Hence, further systematic and standardized large scale studies are suggested in government sectors for prevention and management of these nosocomial infections.

\section{Conclusion}

This study showed bloodstream infection and UTI are the common nosocomial infections among patients in ICU. Our study also revealed that the incidence of infections increases with the use of invasive devices and the geriatric population is highly vulnerable to nosocomial infections. Early recognition of infections and short term use of invasive devices along with proper infection control procedures can significantly decrease the incidence of nosocomial infections in geriatric patients.

\section{References}

1. Garner JS, Jarvis WR, Emori TG, Horan TC, Hughes JM. CDC definitions for nosocomial infections, 1988. Am J Infect Control. 1988;16:128-40.

2. Richards MJ, Edwards JR, Culver DH, Gaynes RP. Nosocomial infections in medical intensive care units in the United States. National Nosocomial Infections Surveillance System. Crit Care Med. 1999;27:887-92.

3. Rahim B, Peyman M, Davood N, Hamid RK. An epidemiological study of nosocomial infections in the patients admitted in the intensive care unit of Urmia Imam Reza Hospital: An etiological investigation. Ann Biol Res. 2011;2:172-8.

4. Ulu-Kilic A, Ahmed SS, Alp E, Do anay M. Challenge of intensive care unitacquired infections and Acinetobacter baumannii in developing countries. OA Crit Care. 2013;1:2.

5. Pratham R, Manmohan S, Vipin R. A retrospective study of nosocomial infections in patients admitted in M.I.C.U.Indian J Pharm Pract. 201 1;4:62-5.

6. Crossley KB, Peterson PK. 5th ed. Philadelphia: 2000. Infection in Elderly, Principles and Practice of Infectious Diseases;pp. 3164-9.

7. Emori TG, Banerjee SN, Culver DH, Gaynes RP, Horan TC, Edwards JR, et al. Nosocomial infections in elderly patients in the United States, 1986-1990. National Nosocomial Infections Surveillance System. Am J Med. 1991;91:289S-93.

8. Richards MJ, Edwards JR, Culver DH, Gaynes RP. Nosocomial infections in combined medical-surgical intensive care units in the United States. Infect Control Hosp Epidemiol. 2000;21:510-5.

9. Mukherjee T, Pramod K, Srinivasan G, Rao MY. Nosocomial infections in geriatric patients admitted in ICU.J Indian Acad Geriatric. 2005;2:6 1-4.

10. Vincent JL, Bihari DJ, Suter PM, Bruining HA, White J, Nicolas-Chanoin MH, et al. The prevalence of nosocomial infection in intensive care units in Europe. Results of the European Prevalence of Infection in Intensive Care (EPIC) Study. EPIC International Advisory Committee.JAMA. 1995;274:639-44.

11. Beaujean DJ, Blok HE, Vandenbroucke-Grauls CM, Weersink AJ, Raymakers JA, Verhoef J. Surveillance of nosocomial infections in geriatric patients. J Hosp Infect. 1997;36:275-84.

12. Suman SM, Alexander AP. Nosocomial infections in the intensive care unit. Anaesth Intensive Care Med.2012;13:204-8. 